Tachycardia

\section{Tachycardia in the presence of a pacemaker}

\section{S Menon, H Hafeez, T Verjee, R Sivakumar}

(4) What is the differential diagnosis for tachycardia with pacing spikes?

(5) What is the management?

Postgrad Med J 2004;80:119.

doi: $10.1136 /$ pmi.2002.004036q

\section{...................}

Authors' affiliations

S Menon, H Hafeez, T Verjee, R Sivakumar,

Department of Medicine, Lister Hospital,

Stevenage, UK

Correspondence to: Dr Sivakumar ; sivasiva51@hotmail.com

(2) Is the pacemaker malfunctioning?

(3) How do you explain the tachycardia with pacing spikes?

Submitted 7 December 2002

Accepted 9 March 2003 years ago for complete heart block. She was tachycardic with a heart rate of around 120 beats/min but haemodynamically stable. A rhythm strip is shown below (see fig 1).

\title{
QUESTIONS
}

(1) What is the electrocardiographic diagnosis?

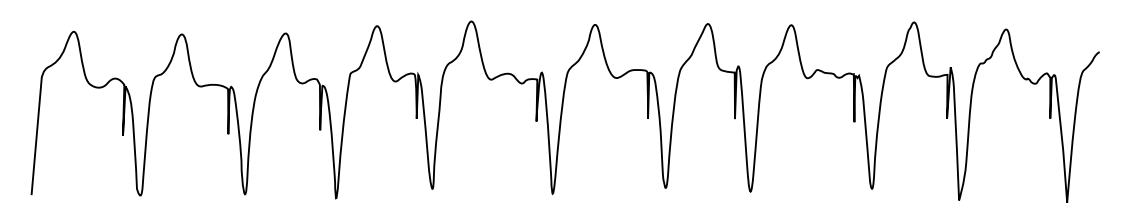

Figure 1 Rhythm strip. 